de lanzarse a considerar la novela sin hilos prestigiosos que la sostengan. Sin toda esa justificación, sin las digresiones que llevan a la autorat a detenerse demasiado y sin necesidad en $A s I$ lay dying y Manhattan transfer, sin la reiterada insistencia en la técnica de montaje cinematográfico que encuentra en $L a$ casa verde (idea extraída de un comentario de Rodríguez Monegal, cf. p. 224), el capítulo hubiera conseguido la coherencia, concisión y solidez que se extraña en todo el libro.

Una línea cronológica une los capítulos. La pauta la dictan las novelas, el momento en que aparecieron, la intención de los autores al recurrir al tema de la selva, cómo lo hacen, qué consiguen. En ese plano, la conclusión es que la selva por lo general es un infierno; a veces será un paraíso, en todos los casos será cruel. Hay en el libro una serie de elementos agrupados pero no hay una estructura que los articule; a causa de esto el trabajo queda reducido a la descripción del material, ciertamente amplio y bien documentado, pero puesto aquí como sumado, sin método que lo armonice. También el estilo de León Hazera contribuye a volver un tanto monótona la lectura. ¿Cómo hablar, por ejemplo, de la selva sin mencionarla continuamente? :Cómo hablar de lo que es de la selva o de su influencia sin decir a cada rato "selvático[ca]"? Para lo primero la autora encuentra la alternativa. de floresta, paisaje. Para lo segundo no encontró, al parecer, alternativa. De ahí que a cada pocas líneas se lea: región selvática, paisaje selvático, habitación selvática, edén selvático, naturaleza selvática, visión selvática, tema selvático, obra selvática (!) [la de Quiroga]; de ahí también que los indios, el ambiente, la zona, el mundo, el destino scan selváticos o selváticas.

Este trabajo fue presentado originalmente como tesis de doctorado en la Universidad George Washington, y pasó a publicación con todas las características de una tesis: el prólogo descriptivo, las conclusiones a cada capítulo, la conclusión final que reitera las parciales, la innecesaria bibliografía general. Pocas veces se encuentran libros que, como éste, concentran trayectorias temáticas de la narrativa hispanoamericana y sacan a luz los datos perdidos y olvidados de nuestra historia literaria; el estudio hubiera ganado en interés si antes de su publicación se lo hubiera sometido a una revisión profunda, no sólo para mejorar rasgos de estilo, sino para que se eliminaran digresiones y repeticiones y consiguiera la energía que está pidiendo a cada página.

M. E. VENilR

El Colegio de Mésico.

Mercedes ReIN, Nicanor Parra y la antipoesia. Universidad de la República, Facultad de Humanidades y Ciencias, Montevideo, 1970; $50 \mathrm{pp}$.

En la "Nota preliminar" a este ensayo la autora da a conocer los propósitos de su investigación y explica algunos fundamentos metodológicos del análisis que hace sobre la obra de Nicanor Parra. En los 
seis capítulos siguientes M. Rein expone las ideas de Parra sobre su poesía, explica el contexto histórico en el que se desarrolla su vocación poética, analiza los libros Poemas y antipoemas, Poemas de salón, $M a$ nifieslo, Canciones rusas y, finalmente, hace una rápida reseña de las últimas series poéticas incluidas en Obra gruesa: "La camisa de fuerza", "Otros poemas" y "Tres poemas".

"E1 propósito fundamental de este trabajo fue realizar un análisis crítico de la antipoesía en la obra de Nicanor Parra" (p. 3) ; con esta frase $M$. Rein plantea la finalidad de su investigación. Un poco más adelante precisa el camino concreto que va a seguir: "... ¿Qué entiende Nicanor Parra por intipoesía y de qué manera -en qué grado- ha realizado este concepto en su obra?" (loc. cit.). En realidad, en los textos no poéticos del escritor chileno que utiliza no hay, en sentido estricto, un concepto de antipoesía. Explica cómo un grupo de poetas de la generación del 38 reacciona contra el hermetismo de la poesía chilena surrealista proponiendo una poesía de la claridad, "claridad conceptual y formal"; cómo este grupo, al cual pertenecía Parra, reacciona contra las convenciones caducas de la sociedad contemporánea, recurriendo al absurdo para romper con la lógica y todas las normas viqentes que sostienen las instituciones anquilosadas. Pero éstas son afirmaciones demasiado generales para poder definir con exactitud lo que es el antipoeta y la antipoesía. La autora precisa algunos temas, determina algunas formas recurrentes en la poesía de Parra y, sin embargo, termina diciendo: "Los límites y propósitos de su antipoesía mal podrían ser definidos, puesto que éstat se confunde en última instancia con su poésía" (p. 16); el concepto de antipoesía es "esencialmente ambiguo, irónico y reversible" (p. 33).

El otro problema planteado en la "Nota preliminar" es el de la valoración. La antipoesía es una especie dentro del género poesía y, por lo tanto, puede discutirse acerca de su calidad artística. Para no caer en observaciones puramente subjetivas, se propone como criterio objetivo de evaluación el de la autenticidad, partiendo de la hipótesis de que ésta es una "aspiración primordial del antipoeta" (p. 4). El concepto de autenticidad se explica dentro de tres ideologías contemporá. neas del mundo occidental: el existencialismo, el marxismo y el surrealismo. Por supuesto, se llega no a uno, sino a tres conceptos de autenticidad y M. Rein reconoce que son divergentes, pero que se suelen mezclar en las interpretaciones que hacemos de los mensajes póticos, "porque constituyen el trasfondo de la poesía contemporánea" (p. 10).

Ya en el análisis concreto de la obra de Parra, emplea nuchas veces la palabra autenticidad, incluso llega a afirmar que Canciones rusas es un libro que se siente como auténtico en las tres dimensiones del tírmino: sin embargo, difícilmente se puede afirmar que el análisis mismo demuestre este tipo de valoración, puesto que está hecho con un método estilístico y las valoraciones son más bien formales e impresionistas. Por ejemplo, refiriéndose al poema "Paisaje", afirma: "Aquí podríamos decir que el antipoema encuentra su poesía en la síntesis, la concentración simbólica, la intensidad y la limpieza del trazo 
descriptivo, la eliminación de la anécdota y las reflexiones abstractas" (pp. 26-27). "En cuanto expresión noble, afinada, sensible, inteligente, el Manifiesto es poesía (o antipoesía) como puede serlo una página o un capítulo de Rayuela" (p. 39).

M. Rein no se limita a discutir el concepto de antipoesía y su valor literario - estos son los fines centrales y explícitos de la investigación-; también se propone la autora caracterizar cada una de las obras de Parra que estudia, establecer líneas de evolución de su poesía, destacar el valor de algunos poemas, analizar desde la métrica hasta los temas más generales (la muerte, la finalidad de la existencia, el tiempo), ubicar históricamente la obra del escritor chileno. Todo esto resulta demasiado extenso y complejo para que pueda ser tratado con relativa profundidad y rigor en las cuarenta páginas, que se dedican a la poesía de Parra. Un buen ejemplo de cómo muchos temas se aprietan en poco espacio es el capítulo tercero, titulado "Las coordenadas históricas". Se discute allí la actitud política del grupo de escritores al que pertenecía Parra y sus relaciones con la literatura europea de vanguardia; se caracteriza el vanguardismo europeo y se examinan las diferencias con los cenáculos vanguardistas latinoamericanos; se compara la poesía de Parra con la de los escritores argentinos que se agruparon en torno a la revista Martin Fierro; se hace un contraste entre Parra por un lado v Huidobro, Vallejo y Neruda, por el otro, y, finalmente, se establece un paralelo entre Nicanor Parra y Cortázar. El capítulo consta sólo de cuatro páginas y media.

El trabajo no tiene límites tan precisos como sugieren los propósitos que se enuncian en las primeras páginas. Es más bien una presentación general de la obra de Nicanor Parra, aunque no se incluyen los dos primeros libros: Cancionero sin nombre y Ejercicios retóricos. Los aspectos más valiosos del ensayo están en la fina sensibilidad con que se comenta algunos poemas y en el hecho de destacar la importancia del plano fónico en la poesía de Parra, especialmente las formas métricas, que la crítica deja generalmente de lado en beneficio de otros niveles más destacadamente visibles.

La investigación ha sido realizada con una bibliografía bastante incompleta - me refiero a la publicada antes de 1970 . No ha utilizado la autora ninguna de las entrevistas hechas a Nicanor Parra y sólo hay referencias a uno de los cuatro prólogos a sus obras. Los artículos de revistas consultados se reducen a menos de la mitad de los que existen; faltan algunos verdaderamente importantes para el tema estudiado, como es el de Federico SCHOPF "Estructura del antipoema" ( $A, 1963$, núm. 399, pp. 140-153). Al parecer, tampoco conoce M. Rein la segunda colección de poemas de Nicanor Parra, "Ejercicios retóricos", publicada en la revista Extremo Sur, 1954, núm. 1, pp. 4-6; es ésta una obra de transición (escrita en 1943) entre Cancionero sin nombre y Poemas y antipoemas.

La bibliografía más completa que conozco sobre Nicanor Parra está en el libro de Leonidas Morales La poesia de Nicanor Parra, Universidad Austral de Chile, Valdivia, Editorial Andrés Bello, Santiago de Chile, 1972. 220 pp. (Col. EFil, anejo 4). En esta misma obra, aparece 
como apéndice una excelente entrevista al poeta chileno, Ia más inportante y extensa que se ha publicado.

Hernin Silva

El Colegio de México.

\section{CARTA DE DARIO PUCCINI A ANTONIO ALATORRE}

Roma, 25 de mayo de 1973.

Querido colega y amigo,

he dejado pasar casi tres meses desde el día en que la Señora Morreale me envió el recorte de su reseña de mi libro sobre Miguel Hernández, que Ud. hizo publicar en el último número de la NRFH. No quería, en efecto, escribirle bajo la primera impresión desagradable que dicha reseña me produjo.

Además, creo firmemente que sea buena regla de los autores, blanco de críticas muy severas y aún injustas, no contestar nada y callarse tranquilamente. A cada uno la libertad de escribir sobre el libro de otra persona lo que se le ocurra.

Pero, como director de tan prestigiosa revista, quiero someterle tres consideraciones, dejando de parte lo que se refiere a los juicios contenidos en la reseña, porque siempre un crítico opina según su cultura y sensibilidad. Por lo tanto, si la Señora Morreale no muestra un trato frecuente con la lengua literaria italiana contemporánea, es algo que sólo le atañe a ella. Para dar un ejemplo, y sólo uno, ella juzga que yo "aflija el italiano con formas inadmisibles" (¿̨inadmisibles en base al juicio de quién? ¿̨de cuál Academia suprema que no existe?) cuando traduzco "las ansias", con el plural "le ansie", olvidando que Pavese escribe "ansie e brividi" en su poesía, con toda la libertad que le otorga el uso libérrimo de la lengua poética.

He aquí mis tres consideraciones:

1) Me parece muy extraño que la NRFH haya aceptado publicar, en 1973, la reseña de un libro que salió en Italia en el año 1966 - un libro viejo de siete años- cuando existe y circula una edición en lengua española del mismo libro publicada en Buenos Aires en el año 1970 (Losada). No se trata sólo de una edición más reciente y con algunas correcciones, sino también de mayor alcance para los lectores del área hispánica. Esta extrañeza está confirmada por otro hecho: veo que en el mismo número salió otra reseña, la de mi Romancero de la Resistencia Española (edición mexicana del año 1967), y no me resulta que la revista haya tomado nunca en cuenta las tres ediciones italianas o las dos francesas del mismo libro, publicadas mucho antes.

2) También me extraña que la revista haya aceptado una reseña donde casi no se habla del libro y de las interpretaciones que propone sobre Hernández y su obra, interpretaciones que merecieron varios comentarios positivos o polémicos, y discute casi exclusivamente de las traducciones italianas que aparecen en las notas. ( $\mathrm{Y}$ no importa que la Señora Morreale nunca tenga en cuenta, a propósito de las traducciones, que se trata de versos y de traducciones libres). Esto de las traducciones en italiano no sé cuanto pueda interesar a lectores de habla hispánica ... Esta consideración y la anterior me hacen pensar en una actitud desfavorable o quizás hostil de su revista hacia mis trabajos, aunque la segunda reseña (por lo que me resulta del 